\title{
APORTES DA ECOLOGIA POLÍTICA PARA A CONSTRUÇÃO DE UMA EDUCAÇÃO AMBIENTAL DE BASE COMUNITÁRIA NO CONTEXTO LATINO-AMERICANO: NARRANDO A EXPERIÊNCIA DE UM CURSO DE EXTENSÃO UNIVERSITÁRIA
}

\section{POLITICAL ECOLOGY SUPPORT FOR THE CONSTRUCTION OF A COMMUNITY-BASED ENVIRONMENTAL EDUCATION IN THE LATIN AMERICAN CONTEXT: NARRATING THE EXPERIENCE OF A UNIVERSITY EXTENSION COURSE}

\author{
Celso Sánchez ${ }^{1}$ \\ Stephanie Di Chiara Salgado ${ }^{2}$ \\ Sônia Terezinha de Oliveira ${ }^{3}$
}

\section{RESUMO}

Este trabalho pretende trazer aportes para consolidação de uma Educação Ambiental (EA) de Base Comunitária, que vem sendo formulada a partir dos acúmulos de pesquisa do Grupo de Estudos em Educação Ambiental desde el Sur (GEASur), através do diálogo entre o campo da EA Crítica em articulação com a Ecologia Política Latino-Americana e a Educação Popular. Para tal, iremos descrever e discutir a experiência de um curso de extensão oferecido pela Universidade Federal do Estado do Rio de Janeiro (UNIRIO), através do GEASur, que ocorreu de 2017 a 2019, em três edições. Para tanto, refletiremos também sobre o papel da extensão universitária na formação de educadores e ativistas socioambientais críticos, com a intenção de responder às demandas da educação ambiental em territórios que enfrentam conflitos ambientais.

Palavras-chave: Curso de Extensão Universitária; Educação Ambiental de Base Comunitária; Ecologia Política; América Latina.

\section{ABSTRACT}

This working tendstobring contributions to the consolidation of a Community-Based Environmental Education (EE), Which hás been formulated fromt here searches of the Group of Studies on Environmental Education desde el Sur (GEASur), through the dialogue between the EE critic fieldin articulation with Latin American Political Ecology and Popular Education. To this end, we willd escribe and discuss the experience of na extension course offered by the Federal University of the State of Rio de Janeiro (UNIRIO), through GEASur, which took place from 2017 to 2019, in three editions. Finally, we will also reflecton the role of university extension in the formation of critical educator sand social and environmental activists, aimingto responding to the role of EE in territories that face environmental conflicts.

keywords: Extension University course; Community-Based Environmental Education; Political Ecology; Latin America.

\footnotetext{
${ }^{1}$ Doutor em Educação (PUC-Rio). Professor Associado da UNIRIO. Departamento de Educação. Coordenador do Grupo de Estudos em Educação Ambiental desde el Sur (GEASur). E-mail: celso.sanchez@hotmail.com.

'Licenciada em Química (UFF). Mestranda em Educação (UNIRIO). Professora do IFRJ-Pinheiral. E-mail: stephsalgado@gmail.com.

${ }^{3}$ Pedagoga (SUAM) e Especialista em Gestão Pública (UCM). Servidora técnico-administrativa da UNIRIO. E-mail: sonia.oliveira@unirio.br.
} 


\section{INTRODUÇÃO}

No Brasil, o princípio da indissociabilidade entre Ensino, Pesquisa e Extensão teve diferentes formas de entendimento. Em alguns momentos era lido como difusão cultural ou científica, prestação de serviço, assistência, desenvolvimento, até que se chegasse à proposta atual estabelecida a partir da criação do Fórum de Pró-Reitores de Extensão das Instituições Públicas de Educação Superior Brasileiras (FORPROEX), e logo em seguida da Rede Nacional de Extensão (RENEX), na qual é compreendida como caminho de consolidação de responsabilidade e compromisso social e como dimensão intrínseca da formação acadêmica e do conhecimento produzidos na e pela Universidade.

Esta proposição de formação dialoga com a perspectiva de Paulo Freire (2007), indissociabilizando a tríade Ensino, Pesquisa e Extensão, isto porque ensinar exige rigorosidade metódica, pesquisa, respeito aos saberes dos educandos, criticidade, reflexão crítica sobre a prática, consciência do inacabamento, respeito à autonomia do ser do educando, apreensão da realidade, convicção de que a mudança é possível, comprometimento, entre outros.

Considerando esse cenário, neste trabalho pretendemos refletir sobre as experiências do "Curso de Extensão em Educação Ambiental de Base Comunitária e Ecologia Política na América Latina", uma atividade que integra ensino, pesquisa e extensão organizada pelo Grupo de Estudos em Educação Ambiental desde elSur (GEASur), da Universidade Federal do Estado do Rio de Janeiro (UNIRIO), que se concentra em estudar práticas pedagógicas de Educação Ambiental (EA) nos contextos formal e não-formal, emergentes das lutas populares, movimentos sociais, populações tradicionais, povos indígenas e grupos em situação de vulnerabilidade socioambiental causados por conflitos ambientais no cenário latino-americano.

Concordamos com Mota Neto (2016) quando diz que "um pensamento não pode ser compreendido fora da estrutura de sentimentos que o constitui" (p. 101). Por isso, ao apresentar nas próximas linhas o GEASur e suas escolhas epistemológicas, estamos na verdade apresentando as estruturas de 
sentimentos que lhe movem e dão sustentação. E estes estão localizados desde el sur, ou seja, ao lado dos esfarrapados do mundo, e junto deles, se descobrindo, sofrendo e lutando ${ }^{4}$. Posicionamos-nos ao sul para saltar 0 cercado conforme proposto pela poeta angolana Paula Tavares (1985). Como uma desobediência epistêmica (Mignolo, 2007), nos posicionamos ao sul, pois chegou a vez de ouvir as Marias Mahis, Marielles, malês (Oliveira et al., 2019).

Sendo assim, Sempre que nos referimos ao sul neste artigo, seja com a palavra sul ou a expressão desde el sur, não estamos nos referindo ao sul geográfico - tudo o que se localiza abaixo da linha do equador -, mas ao sul geopolítico, ou seja, aos países subdesenvolvidos pelo jugo do colonialismo e da colonialidade.

Entendendo-o como um organismo vivo, pulsante e posicionado, 0 GEASur foi formado em 2013, vinculado ao Programa de Pós-Graduação em Educação da UNIRIO, visando articular, desde as perspectivas da interculturalidade crítica e da decolonialidade, as áreas temáticas da Educação Ambiental Crítica e da Educação Popular com a Ecologia Política LatinoAmericana, sempre orientado pela luta por Justiça Ambiental e o combate ao Racismo Ambiental, buscando incorporar a Geopolítica do Meio-Ambiente da América Latina na formulação de uma Educação Ambiental de Base Comunitária através das pesquisas de monografia, mestrado e doutorado.

Para além das pesquisas, temos trabalhado de forma articulada no tripé ensino, pesquisa e extensão, pensando disciplinas de graduação e pósgraduação que discutam temas ligados à perspectiva críticadecolonial, buscando sempre a interlocução com os sujeitos e grupos encobertos pela colonialidade e que estão na ponta da lança em seus territórios. Apesar de pouco valorada no meio acadêmico, a extensão tem recebido atenção especial do GEASur, que vem desenvolvendo diversos projetos ocupando a universidade com movimentos sociais, coletivos estudantis, populações tradicionais, lideranças comunitárias, etc.

\footnotetext{
${ }^{4}$ Estamos dialogando com o epílogo da obra "Pedagogia do Oprimido" de Paulo Freire, que diz: "Aos esfarrapados do mundo e aos que neles se descobrem e, assim descobrindo-se, com eles sofre, mas, sobretudo, com eles lutam".
} 
Um desses projetos de chama Diálogos desde el Sur, que acontece semestralmente, privilegiando intercessores oriundos de espaços nãoacadêmicos. O grupo organiza também exposições fotográficas, poéticas e artísticas em espaços de movimentos sociais, como por exemplo, no espaço Raízes do Brasil, em Santa Teresa, no Rio de Janeiro, ocupado pelo Movimento dos Pequenos Agricultores (MPA), assim como na própria Universidade. Outro projeto de extensão é o CineGEASur, também de ocorrência semestral, promove e difunde prioritariamente o cinema da diáspora afrolatina em parceria com o Cine-Clube Atlântico Negro (CAN).

Nesse sentido, o que se ensaia desde o GEASur é a práxis da ecologia de saberes(Leff, 2006; Santos, 2010), ou seja, do convite ao diálogo e ao desenvolvimento da escuta sensível de alunos da graduação e pós-graduação às narrativas de sujeitos subalternizados e encobertos pela lógica colonial.

Ainda no intuito de fazer com que as pesquisas desenvolvidas em âmbito do programa de pós-graduação furem a bolha da academia e atuem na formação de militantes ambientalistas, educadores, ativistas e líderes comunitários, nasce em 2017 o curso de extensão em Educação Ambiental de Base Comunitária e Ecologia Política na América Latina, que já está em sua terceira edição. Além de ser uma forma que o grupo encontra de dizer acerca de seus acúmulos de pesquisa, como por exemplo, o próprio conceito de Educação Ambiental de Base Comunitária, oriundo de dissertações de mestrado do grupo e em permanente trabalho de formulação (Menezes et al., 2018; Camargo, 2017; Silva, 2016; Aquino, 2018; Oliveira e Sánchez, 2019),este curso surge a partir da identificação de uma demanda latente no campo do ambientalismo por se pensar uma Educação Ambiental contextualizada às realidades locais no contexto latino-americano.

É nesse contexto e com a perspectiva de contribuir com reflexões no campo da EA a partir do eixo que trata sobre formação humana e posicionada na luta contra as opressões sistêmicas cunhadas pela modernidade capitalista, que refletimos sobre a experiência do Curso de Extensão em Ecologia Política e Educação Ambiental de Base Comunitária na América Latina, compreendida enquanto uma proposta pedagógica voltada para a formação de sujeitos 
interessados pelas áreas de educação e meio ambiente. Assim, buscamos provocar reflexões sobre papel social de um grupo de pesquisa em Educação Ambiental a partir de sua atuação nas áreas de ensino, pesquisa e extensão na universidade pública, bem como a importância da associação entre os campos da Ecologia Política Latino-Americana e da Educação Ambiental Crítica para a construção de uma Educação Ambiental de Base Comunitária e territorializada.

\section{A ECOLOGIA POLÍtICA COMO TERRITÓRIO DE DEBATE PARA A EDUCAÇÃO AMBIENTAL}

A América Latina é um território fundado e inventado por meio de um conflito ambiental. Essa poderia ser uma síntese do que se nomeia hegemonicamente como "descobrimento" ao se fazer a leitura da história deste continente a partir da Ecologia Política,sobretudo no que se vem se convencionando como sua escola latino-americana, formulada por autores como Hector Alimonda, Arturo Escobar, Carlos Walter Porto-Gonçalves, Maristella Svampa, Catalina Pérez, entre outros.

Em função do que nomearemos como o mito fundacional da América Latina: sua invasão desde 1492, com instauração de um conflito ambiental permanente; incidiremos ao longo deste texto sobre a necessidade de se pensar uma Educação Ambiental atrelada aos territórios em conflitos ambientais e, portanto, em interlocução com o campo da Ecologia Política. Para trazer a abordagem da Ecologia Política, situaremos nossas reflexões em consonância com as formulações do Grupo de Trabalho Ecologia Política desde América Latina / AbyaYala ${ }^{5}$ da $\operatorname{CLACSO}^{6}$, que vem organizando diversas conferências e publicações buscando consolidar uma perspectiva latino-americana para o campo da ecologia política.

\footnotetext{
${ }^{5}$ AbyaYala é como os povos originários da região hoje conhecida como Panamá, em particular o povo Kuna, nominam o continente latino-americano.

${ }^{6}$ Conselho Latino-Americano e Caribenho de Ciências Sociais (CLACSO), instituição internacional não governamental criada em 1967 e que reúnem intelectuais e movimentos sociais de todo o mundo implicados em repensar, desde uma perspectiva crítica e plural, a problemática das sociedades latino-americanas e caribenhas em sua integralidade.
} 
Logo na apresentação do primeiro volume da coleção "Ecología Política Latinoamericana", Catalina Pérez e Facundo Martín (2017) delineiam que este se trata de um campo de análise crítica, seguindo o legado da tradição crítica latino-americana, e de enunciação plural, sendo interdisciplinar, buscando uma interseção entre a história ambiental e política, a geografia crítica, os estudos culturais e o pensamento ambiental, por exemplo.

Seu grande interesse e legado vêm sendo a reescrita da história desta região a partir da reconstrução das relações entre sociedade, cultura e natureza. Propondo refletir sobre a complexa problemática da formação de identidades nas sociedades latino-americanas, suas elaborações teóricas possuem profundo alinhamento com o grupo Modernidade/Colonialidade e as teorias críticas decoloniais. Entendendo que a colonização, ao abrir as veias da América Latina, causou rupturas profundas nas relações entre seres humanosnatureza, forjando identidades subalternizadas, e impondo geopolíticas hierarquicamente construídas desde a racialização da população mundial, colocando os povos e os territórios colonizados em posições subalternas.

Nas palavras de Alimonda, encontramos uma definição do que seria a Ecologia Política:

(...) propongo que laecopol [ecologia política] es un campo de discusióninter y transdisciplinario que reflexiona y discute las relaciones de poder en torno de lanaturaleza, en términos de sufabricación social, apropiación y control por parte de diferentes agentes socio-políticos. (Alimonda, 2011: 46)

Ao discutir as diferentes formas de fabricação, apropriação social e controle da natureza, a ecologia política está desvelando as relações de poder que se constituem nos territórios em níveis local e global, mostrando que o entendimento da pauta ambiental não é uma coisa única, não é consensual, pelo contrário, que há divergências profundas na maneira como diferentes grupos interagem com a natureza. Tais divergências vêm instaurando neste continente permanentes conflitos e causado o que Quiñonez (2018) sistematiza como um Ecoetnogenocídio.

Ou seja, desde a colonização, a América Latina vem sofrendo um processo de espoliação intensa, com sua natureza transformada em recursos naturais que alimentam o desenvolvimento da Europa e dos países centrais do 
capitalismo. Nossas florestas, nossos rios, nossos biomas -nossa natureza!vem sendo assassinados, sofrendo um ecocídio.

Da descoberta das Américas decorre o que Dussel (1993) nomera como o encobrimento do outro, processo que Quijano (2007) sistematiza como a criação de identidades subalternas racializadas - índios e negros - que serão determinantes para a instauração de um novo padrão de poder mundializado, que afetará a divisão internacional do trabalho e que perdura desde a colonização até os dias atuais: a colonialidade do poder.

\begin{abstract}
La colonialidad es uno de los elementos constitutivos y específicos delpatrón mundial de poder capitalista. Se funda em la imposición de una clasificación racial / étnica de la población del mundo como piedra angular de dicho patrón de poder, y opera en cada uno de los planos, ámbitos y dimensiones, materiales y subjetivas, de la existencia cotidiana y a escala social. Se origina y mundializa a partir de América. Com la constitución de América (Latina), em el mismo momento y em el mismomovimiento histórico, el emergente poder capitalista se hace mundial, sus centros hegemónicos se localizan em las zonas situadas sobre el Atlántico -que después se identificarán como Europa-, y como ejes centrales de su nuevo patrón de dominación se establecen también la colonialidad y la modernidad. Em otras palabras: con América (Latina) el capitalismo se hace mundial, eurocentrado y la colonialidad y la modernidad se instalan, hasta hoy, como los ejes constitutivos de este específico patrón de poder. (Quijano, 2007: 285-286)
\end{abstract}

Com a colonização e o colonialismo e a instauração da colonialidade do poder, índios e negros foram transformados em não-seres, ou na melhor das hipóteses, em humanos inferiores, cujas vidas eram - e seguem sendo matáveis. Por isso, não se trata de um genocídio, mas de um etnocídio - a morte era direcionada àqueles cuja identidade foi forjada pela colonialidade. $\mathrm{E}$ veja que a morte desses tinha relação intrínseca com a exploração e a espoliação dos territórios colonizados. Por essa razão, o Ecoetnogenocídio está na raiz da colonialidade da natureza, conceito que discutiremos adiante.

Pode-se entender, pela ótica desse grupo, a modernidade como relações de dominação intersubjetivas e geopolíticas que foram sendo conformadas com as experiências do processo de colonização e consequentemente com o colonialismo e a colonialidade (Quijano, 2007). É importante pontuar que a mudança dos sufixos nos termos colonização, colonialismo e colonialidade modificam seus significados. Sem dúvida há uma 
relação visceral entre esses processos, mas enquanto a colonização e o colonialismo são fenômenos históricos datados e que se expressaram em diversos territórios durante as expansões imperiais, a colonialidade se inaugura com a "descoberta" da América Latina e não terminou com o fim do colonialismo. A colonialidade é aquilo que perdura, foi instaurado pela violência colonial e segue em curso. Nessa leitura, a decolonialiade aparece como sinônimo de "basta", "agora não mais", "não aceitamos". Ou seja, como interrupção deste violento processo de dominação material, mas também intersubjetivo.

Voltando nossas atenções para a síntese de que a América Latina foi fundada num conflito ambiental, a ideia de colonialidade da natureza (Alimonda, 2011; Walsh, 2017) aparece como uma abordagem importante para ser levado em consideração, no sentido de se pensar um projeto políticopedagógico combativo aos conceitos de desenvolvimento, ordem e progresso, instaurados pela leitura que a modernidade ocidental fez do território latinoamericano.

\begin{abstract}
[lanaturaleza] aparece ante elpensamiento hegemónico global y ante las elites dominantes de laregión como unespacio subalterno, que puede ser explotado, arrasado, reconfigurado, segúnlasnecesidades de los regímenes de acumulación vigentes. Alo largo de cinco siglos, ecosistemasenterosfueron arrasados por laimplantación de monocultivos de exportación. Fauna, flora, humanos, fueronvíctimas de invasiones biológicas de competidores europeos 0 de enfermedades. Hoy es el turno de lahiperminería a cieloabierto, de losmonocultivos de soja y agrocombustiblescon insumos químicos que arrasan ambientes enteros -inclusive a los humanos-, de los grandes proyectoshidroeléctricos 0 de lasvías de comunicaciónenlaamazonia, como infraestructura de nuevos ciclos exportadores. (...) una ruptura a nivel global del metabolismo sociedad-naturaleza, que penaliza crecientemente a lanaturalezalatinoamericana y a lospueblos que enellahacensu vida (O'Connor, 2001 in Alimonda, 2011: 22).
\end{abstract}

Alimonda, em sua obra "La naturaleza Colonizada" aponta como a natureza dos países de capitalismo periférico foi transformada no que podemos associar como tremendas zonas de sacrifício (Acselrad, 2004), ou seja, territórios disponíveis ao abate frente ao processo de acumulação incessante do capital. Teritórios que podem ser devastados através dos extrativismos em mega-escala como a mineração e os monocultivos. Indo além, podemos entender também a colonialidade da natureza nas dimensões intra-subjetivas, 
pois ao modificar as dinâmicas territoriais das regiões, transformando indígenas em mineiros, por exemplo, se modificam suas identidades. Por isso mesmo, Walsh aborda a colonialidade da natureza como uma colonialidade cosmogônica, uma colonialidade da existência-vida dos povos indígenas, afrodescendentes e campesinos.

\begin{abstract}
No es fortuito que los territorios más afectados por la mineria, el petroleo, la extracción de gas, el fracking, los monocultivos, la agroindustria y el megaturismo, son los territorios, em su mayoría, afrodescendientes, indígenas y campesinos. Son territorios donde moran los epistemes de seres y saberes colectivos, las estructuras de memoria colectiva y de la existencia-vida, donde la naturaleza entendida como una relacionalidad integral em el cuallos seres humanos junto com los otros seres forman parte - juega un rol fundamental. Hoy la colonialidad de la naturaleza representa la conjunción de la colonialidad del poder, saber y ser; es la colonialdad de la existencia-vida. (Walsh, 2017: 25)
\end{abstract}

Sendo assim, podemos falar que além da América Latina se configurar em uma grande zona de sacrifício, os atores sociais que resistem ao modo de vida instaurado pelo rolo compressor do desenvolvimento, além de espoliados e subalternizados, se configura como populações de sacrifício (Rios, 2016), que possuem classe e raça, constituindo também o Racismo Ambiental (Bullard, 2005). A pesquisa de Wanderley (2016) retrata perfeitamente este cenário. Ao fazer o levantamento das comunidades atingidas pelo rompimento da barragem de rejeito de Fundão da Samarco Mineração, em Mariana (MG), constatou-se que, as principais comunidades atingidas pela lama eram predominantemente compostas por negros, todas contendo populações acima de $60 \%$ de autodeclarados negros de acordo com o censo do IBGE de 2010.

Dessa forma, ocorre uma distribuição desigual dos danos ambientais sobre os territórios, determinando uma geopolítica do meio-ambiente. Por isso, pensar uma Educação Ambiental com os pés fincados na América Latina, territorializada, requer posicioná-la em luta por justiça ambiental, ao lado dos esfarrapados do mundo, contra o racismo ambiental. Por isso, a EA de Base Comunitária está atenta ao tripé território, territorialização e territolialidades, conforme sistematizado por Porto-Gonçalves:

O território é uma categoria espessa que pressupõe um espaço geográfico que é apropriado e esse processo de apropriação - 
territorialização- enseja identidades -territorialidades- que estão inscritas em processos sendo, portanto, dinâmicas e mutáveis, materializando em cada momento uma determinada ordem, uma determinada configuração territorial, uma topologia social (Bourdieu, 1989). Estamos longe, pois, de um espaço-substância e, sim, diante de uma tríade relacional território-territorialidade-territorialização. A sociedade se territorializa sendo o território sua condição de existência material. (Porto Gonçalves, 2002: 230)

Ao analisarmos os territórios e seus processos de territorialização por meio dos conflitos ambientais, consideramos também que alguns grupos têm empreendido lutas pela "reapropriação social da natureza". Essa categoria foi defendida por Leff (2006) ao compreender que o ambiente se apresenta como um sistema complexo e objeto de um processo de reapropriação social que se materializa a partir das estratégias de lutas e (re) existências destes grupos, que ajudam a revelar, mais claramente, como se manifestam as especificidades materiais e simbólicas que envolvem os processos conflitivos.

Tais lutas por reapropriação social da natureza estão associadas também às lutas pela existência de diferentes territorialidades, de diferentes identidades territoriais, que se constituem num processo constante de territorialização, desterritorialização e re-territorialização. Trata-se de um fenômeno complexo, onde territorialidades, des-territorialidades e reterritorialidades acontecem, desenhando o espaço geográfico. Nessa complexa teia, atuam instituições, processos políticos e pedagógicos. Stortti (2019), investigando os afetados pela indústria do petróleo, em Caxias, Baixada Fluminense, procura demonstrar como os sujeitos dessa luta se constituem no que denomina como sujeitos dos territórios. Nesse sentido, o autor procura entender como o esforço desses sujeitos na luta pela garantia do direito de existir no território constitui uma territoriania. Portanto, Marcelo Stortti procura nos mostrar é que esses sujeitos dos territórios não estão apenas reivindicando direitos como cidadãos, ou seja, exercendo sua cidadania; estão sim, disputando a ideia mesma de direitos a partir do direito de existir no território, porque se constituem enquanto sujeitos dos territórios que compreendem a sua identidade territorializada - sua territorialidade - como um direito.

É nesse sentido que admitimos que em cada um desses enfrentamentos aos conflitos ambientais desenvolvem-se saberes e epistemologias populares, 
também entendidas como Epistemologias do Sul (Santos, 2010). Do ponto de vista epistêmico, o que essas críticas contestam implicitamente é o processo contínuo de violência colonial, o qual consideramos sua emergência no debate da Educação Ambiental crítica frente à sua implicação nas relações sociedadenatureza.

Nesta linha, o GEASur/UNIRIO vem pensando e formulando o conceito de Educação Ambiental de Base Comunitária, a partir de uma articulação entre a perspectiva de Educação Ambiental Crítica e Transformadora e os acúmulos do que estamos entendendo como sendo um Legado da América Latina (Camargo, 2017). Com relação a este Legado, nos referimos a um conjunto de teorias e práticas desenvolvidas em uma estreita parceria entre intelectuais comprometidos e setores populares e movimentos sociais atuantes no Sul global.

Sendo a EA um campo com múltiplas identidades (Layrargues, 2004), nos alinhamos à sua vertente crítica descrita por Loureiro (2009), Tozoni-Reis (2002) e Layrargues (2002), uma vez que ela favorece uma crítica ao padrão de sociedade vigente e por não comportar separações entre cultura e natureza no entendimento da questão ambiental. Como condição para se estabelecer novas relações sociedade-natureza, essa perspectiva da EA nos é cara, pois visa a superação das relações sociais que determinam as formas de expropriação e dominação na sociedade.

Uma EA crítica que trata dos legados pedagógicos das lutas sociais é o ponto de partida para se pensar o que temos nomeado como Educação Ambiental de Base Comunitária. Esta linha se constrói para e com as comunidades, atenta ao fortalecimento das suas territorialidades e do cuidado com o bem comum. Ao valorizar as histórias de vida, a memória oral, a cultura popular e o saber-fazer local, esta escolha se estrutura em diálogo com os sujeitos (Camargo, 2017). Os conhecimentos comunitários se integram aos acadêmicos na compreensão, ação e participação dos sujeitos sociais coletivos. Entendemos que das lutas que educam na América Latina emerge a mobilização social, a práxis libertadora e a busca pela re-existência, identificando as mulheres como principais lideranças desde onde o 
conhecimento germina (Pelacani, 2018). Fundamentada no referencial da pedagogia de Paulo Freire e da Investigação Ação Participante de Fals Borda, que caracterizam uma pesquisa comprometida com a realidade social, articulase então à Educação Ambiental de Crítica Transformadora à Educação Popular, a fim de produzir uma Educação Ambiental de Base Comunitária.

Camargo (2017), em sua dissertação de mestrado procura discutir um pouco da trajetória de formulação do que seria uma EA de Base Comunitária, que segundo sua pesquisa, começa a se sistematizar a partir da fala de Enrique Leff na abertura do IV Congresso Iberoamericano de Educação Ambiental $^{7}$, que tinha como tema Educação Ambiental Comunitária, entendendo-a como o diálogo entre o saber popular e o saber científico, entre o teórico e o prático, possuindo caráter epistemológico-pedagógico-político, ou seja, posicionado em contraposição ao que seria uma Educação Ambiental Hegemônica que se baseia na imposição de uma mentalidade externa, na aplicação de projetos prontos, ou seja, uma educação ambiental reprodutora e colonizadora (Camargo, 2017, p. 86).

Além de dialogar com a construção teoria proposta por Leff e demais pesquisadores no decorrer do IV Congresso Iberoamericano de Educação Ambiental, Camargo apresenta as elaborações e reflexões no âmbito do GEASur/UNIRIO, através de seu esforço de pesquisa em monografias, dissertações e teses, para a sistematização do conceito de Educação Ambiental de Base Comunitária. Dessa forma, o autor elenca 12 pontos que considera como orientadores para uma concepção de EA de Base Comunitária:

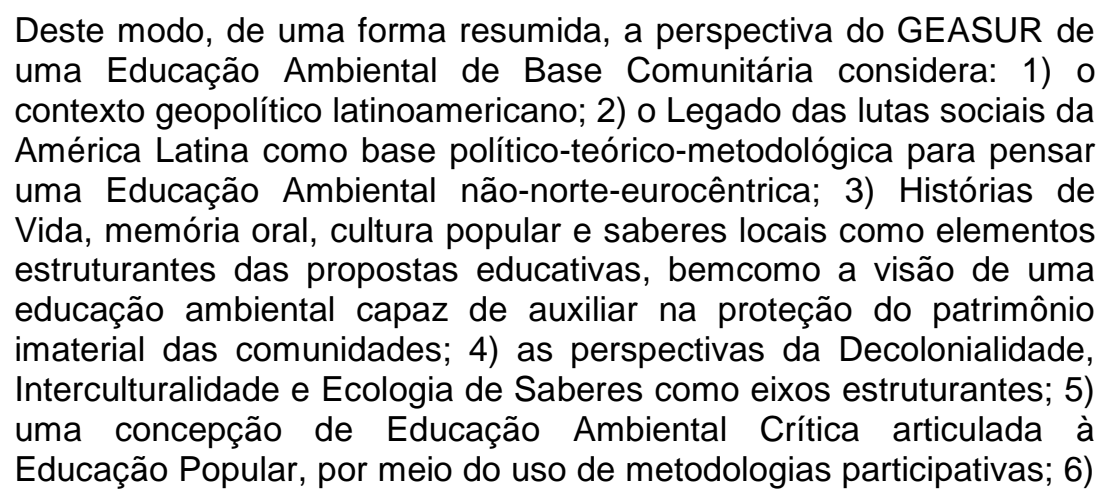

\footnotetext{
${ }^{7}$ Link para Conferência de Abertura do VII Congresso Iberoamericano de Educação Ambiental em:<https://youtu.be/8DSVb7sZ-vc>
} 


\begin{abstract}
a visão da Educação Ambiental enquanto uma ferramenta de gestão popular dos recursos naturais; 7) Paulo Freire como referencial teórico-metodológio-político para a práxis de Educação Ambiental; 8) Educação Ambiental para a Justiça Socioambiental; 9) Pesquisa Sentipensante, investigação comprometida com a realidade social; 10) uma proposta Educativa que articula concepções de Educação Não Formal, Educação Formal e Educação Informal; 11) a dimensão Humana-Cultural-Política-Dinâmica do Meio Ambiente, ou seja, entendendo o Meio Ambiente como um processo, uma elaboração constante, produto das relações entre o ser humano e seu meio; 12) Importância da Dimensão Imaterial das relações entre Humanos e Natureza, com destaque à Espiritualidade e à Transcendência como elementos dialogantes com o campo da Educação Ambiental. (Camargo, 2017: 88-89)
\end{abstract}

Nesse contexto, o GEASur se alinha à tendência crítica, mas com o diferencial de dialogar com o acervo teórico e prático da América Latina, ressignificando este debate. Pensamos política e ideologicamente esse campo contraditório a partir do diálogo com a Ecologia Política e com a temática dos "conflitos ambientais", tema comumente ocultado nas discussões dentro do campo da EA, pois evidencia os papéis de cada ator social envolvido nestes. Um dos interesses centrais nas investigações do GEASur é justamente a pedagogia que emerge de tais conflitos (Kassidou, 2015; Aquino, 2018;Stortti, 2019).

\title{
PELAS BRECHAS: EDUCAÇÃO AMBIENTAL DE BASE COMUNITÁRIA OCUPANDO A UNIVERSIDADE
}

A ideia de se oferecer um curso de extensão em Educação Ambiental de Base Comunitária e Ecologia Política na América Latina nasce a partir do compromisso social do grupo de pesquisa em compartilhar suas produções e reflexões sobre o campo da EA, fortalecendo a formação de ambientalistas, educadores formais e não-formais, lideranças comunitárias e representantes de movimentos sociais, coletivos de estudantes etc., dentro da perspectiva crítica latino-americana, demanda que vem sendo apontada pelos Fóruns e Congressos de Educação Ambiental, onde ainda se nota uma propagação majoritária das vertentes hegemônicas sobre a EA, ligadas às pautas do culto ao silvestre e a preservação ambiental e/ou ao desenvolvimento sustentável, onde se propaga uma ideia homogênea de seres humanos destruidores da natureza (Layrargues, 2014). 
Em termos de delimitação metodológica para a construção deste artigo, utilizamos a análise documental com base nos Relatórios Técnicos do Curso de Extensão elaborados internamente pelo GEASur, nas informações veiculadas nas mídias sociais e no site do grupo de pesquisa.

As três edições do curso aconteceram anualmente de 2017 a 2019, majoritariamente no período de junho a agosto, sempre aos sábados na parte da tarde e com 5 encontros, totalizando uma carga horária de 25 horas. A proposta foi construída com o propósito de, a cada aula, unir um acadêmico e um representante de movimento social (e/ou população tradicional), buscando desta forma suscitar debates entre pesquisadores e movimentos sociais sob a perspectiva do que teoricamente se aproxima do que Leff (2006) e Santos (2010) nomeiam como Ecologia de Saberes, com vistas a promover o interrelacionamento entre os diversos campos de conhecimentos, trazendo para o âmbito estrutural do curso a essência do GEASur. Os temas de cada aula foram debatidos e pensados de acordo com os acúmulos do grupo de pesquisa e também em interface com as temáticas pulsantes na atual conjuntura políticosocial e de relevância para os campos da Educação Ambiental e da Ecologia Política Latino-Americana.

Por isso, nas três edições trouxemos nas aulas iniciais os temas da Educação ambiental desde el Sur e da articulação entre EA crítica, Ecologia Política e Justiça Ambiental, buscando fortalecer esse entrelaçamento e compartilhar, ano após ano, o avanço na compreensão do que seria a identidade desde el sur para a EA, ou seja, como o Giro Decolonial e a educação popular vêm trazendo seus aportes para este campo. Os demais temas foram atravessados pela temática do Racismo Ambiental, da interculturalidade crítica, dos ecofeminismos, dos neoextrativismos, da soberania alimentar, da agroecologia, das discussões metodológicas populares, entre outros.

Ao público de interesse, buscou-se direcionar a divulgação do Curso de Extensão para estudantes de graduação e pós-graduação, professores e educadores populares, lideranças comunitárias, militantes de movimentos sociais, representantes de Redes de Articulação e os demais interessados nas 
temáticas, não havendo restrições quanto ao nível de escolaridade ou qualquer outro critério prévio. Dessa forma, os participantesse caracterizaram por um público amplo e diversificado, o que permitiu ao GEASur oportunizar o acesso dos diferentes sujeitos sociais ao ambiente da universidade pública.

Para fins de planejamento e implementação deste curso, optou-se por organizar Grupos de Trabalho (GT) compostos por membros do GEASur. O GT de Extensão e Formação ficou responsável por toda a concepção do Curso, desde a elaboração do Projeto do Curso, o processo que envolveu a mobilização e divulgação do mesmo, o convite aos professores/palestrantes e toda a estruturação para operacionalizar o curso. Outros GTs foram criados conforme as demandas organizativas, como o GT de audiovisual e o GT cultural, além da equipe de apoio operacional para o momento do lanche coletivo e das inscrições.

A divulgação do curso, em suas três edições, foi realizada por meios eletrônicos (e-mail, Facebook, WhatsApp e nos sites institucionais do GEASur e da UNIRIO), Jornal da Associação dos Servidores Técnicos Administrativos e também dos docente da UNIRIO - ASUNIRIO e ADUNIRIO (impresso e online), e com cartazes impressos que foram anexados em locais estratégicos para ampla divulgação, distribuídos também para os grupos parceiros e apoiadores na organização.

Houve um esforço de se procurar parceiros institucionais, que incluíram a UFF-Angra dos Reis, onde o projeto se encontra cadastrado na pró-reitoria de extensão, sob coordenação da profa. Dra. Inny Accioly; o IFRJ, onde o projeto está cadastrado junto à diretoria de pesquisa e extensão do campus Pinheiral e foi divulgado pela Gestão Ambiental da instituição, tendo a profa. Stephanie Salgado como coordenadora da proposta; o LIEAS-UFRJ, sob coordenação do prof. Dr. Frederico Loureiro; além da Universidade Estadual do Rio Grande do Norte (UERN), o Grupo de Relações Internacionais do Sul Global (GRISul), o Instituto de Biodiversidade e Sustentabilidade (NUPEM/UFRJ), Associação de Educadores da América Latina e do Caribe (AELAC), o Instituto de Políticas Alternativas para o Cone Sul (PACS), o Grupo de Estudos em Educação Ambiental (GEA/UFJF), o Laboratório Memórias, 
Territórios e Ocupações Rastros Sensíveis (LABMENS/Eicos-UFRJ), a Associação de Docentes da Universidade Federal do Estado do Rio de Janeiro (ADUNIRIO).
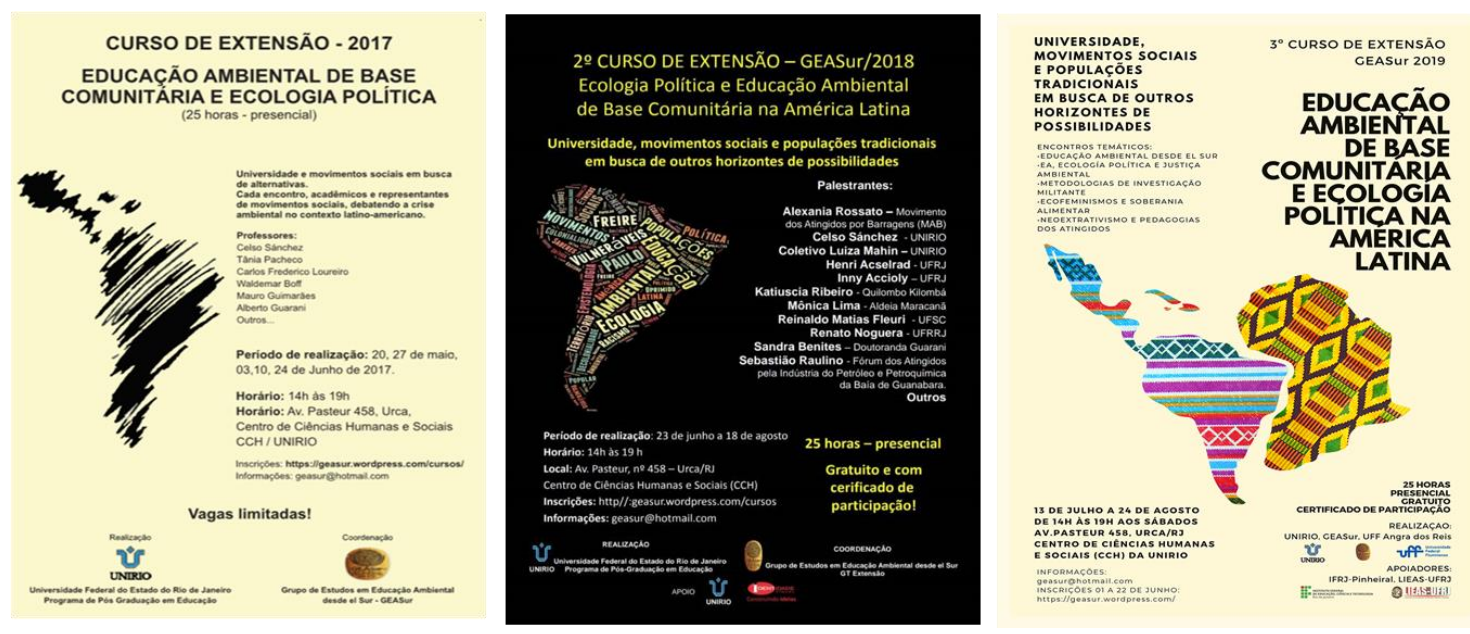

Figura 1 - Cartazes de divulgação do Curso de Extensão em Educação Ambiental de Base Comunitária e Ecologia Política na América Latina

Para fins de detalhamento, o quadro a seguir (tabela 1) apresenta a estruturação geral do I Curso, com os docentes convidados e os respectivos conteúdos abordados, assim como o número de alunos presentes em cada aula.

Tabela 1 - Programação do I Curso de Extensão (2017)

\begin{tabular}{|c|c|c|c|c|}
\hline Data & Tema do dia & Horário & Convidados & Participantes \\
\hline$\underset{i}{20 / m a}$ & $\begin{array}{l}\text { Educação Ambiental } \\
\text { desde elSur: } \\
\text { perspectivas políticas } \\
\text { e epistemológicas }\end{array}$ & $\begin{array}{c}14 \mathrm{~h} \text { às } \\
19 \mathrm{~h}\end{array}$ & $\begin{array}{l}\text { 10 Bloco: Celso Sánchez e Leonardo } \\
\text { Castro (Unirio) } \\
\text { 2 Bloco:Cândido Mendes (Instituto } \\
\text { Bem) }\end{array}$ & 122 \\
\hline$\underset{i}{27 / m a}$ & Racismo Ambiental & $\begin{array}{c}14 \mathrm{~h} \text { às } \\
19 \mathrm{~h}\end{array}$ & $\begin{array}{l}\text { 10 Bloco: Tânia Pacheco (Fiocruz) } \\
\text { 2o Bloco: Clementino Júnior } \\
\text { (Cineclube Atlântico Negro) }\end{array}$ & 112 \\
\hline 10/jun & $\begin{array}{l}\text { Educação Popular no } \\
\text { contexto ambiental }\end{array}$ & $\begin{array}{c}14 \mathrm{~h} \text { às } \\
19 \mathrm{~h}\end{array}$ & $\begin{array}{c}\text { 10 Bloco: Diego Chabalgoity (UFF) e } \\
\text { Waldemar Boff (Água Doce) } \\
\text { 2o Bloco: Sandra Benites (Etnia } \\
\text { Guarani) }\end{array}$ & 94 \\
\hline 24/jun & $\begin{array}{l}\text { Educação e Ecologia } \\
\text { Política: a perspectiva } \\
\text { dos conflitos } \\
\text { ambientais }\end{array}$ & $\begin{array}{c}14 \mathrm{~h} \text { às } \\
19 \mathrm{~h}\end{array}$ & $\begin{array}{l}\text { 10 Bloco: Carlos Frederico Loureiro } \\
\text { (UFRJ) } \\
\text { 20 Bloco:Wíria Alcântara (SEPE) }\end{array}$ & 92 \\
\hline 01/jul & $\begin{array}{l}\text { Epistemologias } \\
\text { outras no processo }\end{array}$ & $\begin{array}{c}14 \mathrm{~h} \text { às } \\
19 \mathrm{~h}\end{array}$ & $\begin{array}{l}\text { 10 Bloco: Mauro Guimarães (UFRRJ) } \\
\text { 2o Bloco: Alberto Álvares (Etnia }\end{array}$ & 75 \\
\hline
\end{tabular}




\begin{tabular}{|c|c|c|c|c|}
\hline & $\begin{array}{c}\text { formativo em } \\
\text { Educação Ambiental }\end{array}$ & & Guarani) & \\
\hline
\end{tabular}

$\mathrm{Na} 1^{\text {a }}$ edição do curso, contamos com 204 inscritos, havendo estudantes de graduação e pós-graduação, professores das redes pública e privada de ensino, servidores públicos de órgãos ambientais, representantes de organizações não governamentais e do setor privado, além de pessoas ligadas aos movimentos sociais. Em média, o curso atingiu um número de 100 participantes em cada encontro. Ao final, como registro e material de divulgação, foi elaborado um vídeo-síntese do curso, que se encontra disponível no canal do YouTube do GEASur/Unirio ${ }^{8}$.

É importante pontuar que da $1^{\text {a }}$ para a $2^{2}$ edição do curso houve a inclusão de atividades culturais na programação, buscando a cada encontro proporcionar um espaço de exposições artísticas como forma de estimular múltiplas linguagens na abordagem socioambiental, fortalecendo também os artistas independentes do nosso território, que têm a arte como resistência e anúncio de novos mundos. Também organizamos um uma atração cultural para o momento de encerramento do curso com a roda de samba "Samba em Resistência", protagonizada pela cantora e mestranda do Programa de PósGraduação em Educação da UNIRIO, Juliana Barbosa.

Além disso, cabe ressaltar um aumento no número de inscritos, atingindo a marca de 320 inscrições, demonstrando o interesse de acadêmicos, pesquisadores, coletivos, trabalhadores de instituições públicas e privadas e movimentos sociais na temática da Educação Ambiental contextualizada ao território latino-americano e em interface com a Ecologia Política.O quadro a seguir (tabela 2) apresenta a estruturação geral do IICurso, com os docentes convidados e os respectivos conteúdos abordados, assim como, o número de alunos presentes em cada aula.

\footnotetext{
${ }^{8}$ Clipe do I e II Curso de Extensão em "Educação Ambiental de Base Comunitária e Ecologia Política na América Latina" organizado pelo Grupo de Estudos em Educação Ambiental Desde el Sur (GEASur/UNIRIO) em 2017 e 2018: https://www.youtube.com/watch?v=9HfvzBszXZk.
} 
Tabela 2 - Programação do II Curso de Extensão (2018)

\begin{tabular}{|c|c|c|c|c|c|}
\hline Data & Tema do dia & Horário & Atividade & Convidados & Participantes \\
\hline \multirow[t]{2}{*}{ 23/jun } & \multirow[t]{2}{*}{$\begin{array}{l}\text { Educação } \\
\text { Ambiental desde } \\
\text { el Sur e Práticas } \\
\text { Educativas de } \\
\text { Base Popular }\end{array}$} & \multirow[t]{2}{*}{$\begin{array}{c}14 \mathrm{~h} \text { às } \\
19 \mathrm{~h}\end{array}$} & Aula & $\begin{array}{l}\text { 10 Bloco: Celso Sánchez e } \\
\text { Leonardo Castro (Unirio) } \\
\text { 2o Bloco: Seimour Pereira } \\
\text { (Coletivo Negro Luisa Mahin) } \\
\text { e Sandra Benites (Etnia } \\
\text { Guarani; Doutoranda em } \\
\text { Antropoloia Social/UFRJ) } \\
\text { Mediador: Cândido Rafael } \\
\text { Mendes (Instituto Bem) }\end{array}$ & \multirow[t]{2}{*}{176} \\
\hline & & & Exposição & $\begin{array}{l}\text { "Varais na paisagem” (Tita } \\
\text { Bevilaqua); "Los muros" e } \\
\text { "(Foto)escrevivência" } \\
\text { (Bárbara Pelacani) }\end{array}$ & \\
\hline \multirow{3}{*}{ 07/jul } & \multirow{3}{*}{$\begin{array}{l}\text { Justiça Ambiental } \\
\text { no contexto dos } \\
\text { conflitos } \\
\text { ambientais }\end{array}$} & $\begin{array}{c}9 \mathrm{~h} \text { às } \\
12 \mathrm{~h}\end{array}$ & Oficina & $\begin{array}{l}\text { "O Corpo Político: dança } \\
\text { como ação coletiva entre a } \\
\text { América Latina e os Estados } \\
\text { Unidos" } \\
\text { Ministrantes: Camila Daniel } \\
\text { (UFRRJ-Brasil), Franca Muller } \\
\text { Paz (Peru/EUA), Mariana } \\
\text { Castañeda Lopez } \\
\text { (México/EUA), Gustavo Omar } \\
\text { (Peru/Brasil). }\end{array}$ & \multirow{3}{*}{$\begin{array}{l}\text { Aula: } 146 \\
\text { Oficina: } 15\end{array}$} \\
\hline & & \multirow{2}{*}{$\begin{array}{c}14 \mathrm{~h} \text { às } \\
19 \mathrm{~h}\end{array}$} & Aula & $\begin{array}{l}\text { 1- Bloco: Henri Acselrad } \\
\text { (UFRJ) } \\
\text { 2o Bloco: Sebastião Raulino } \\
\text { (FAPP) } \\
\text { Mediadora: Anne Kassiadou } \\
\text { (Unirio/GEASur) }\end{array}$ & \\
\hline & & & Exposição & $\begin{array}{l}\text { "Pensamento desde el Sur" e } \\
\text { "Memórias sobre lendas, } \\
\text { rezas e garrafadas: cadernos } \\
\text { de viagens ao Jequitinhonha" } \\
\text { (Daniel Renaud) }\end{array}$ & \\
\hline \multirow[t]{2}{*}{$21 / \mathrm{jul}$} & \multirow{2}{*}{$\begin{array}{l}\text { Conceito de } \\
\text { Totalidade para } \\
\text { subsidiar práticas } \\
\text { em Educação } \\
\text { Ambiental }\end{array}$} & \multirow[t]{2}{*}{$\begin{array}{c}14 \mathrm{~h} \text { às } \\
19 \mathrm{~h}\end{array}$} & $\begin{array}{l}\text { Aula de } \\
\text { campo }\end{array}$ & $\begin{array}{l}\text { 10 Bloco: Inny Accioly (UFRJ) } \\
\text { 2o Bloco: Mônica Lima } \\
\text { (Aldeia Maracanã) }\end{array}$ & \multirow[t]{2}{*}{92} \\
\hline & & & Exposição & Artesanato Indígena & \\
\hline 04/ago & $\begin{array}{c}\text { Práticas } \\
\text { educativas } \\
\text { ambientais de } \\
\text { base comunitária e } \\
\text { pedagogia da } \\
\text { pluriversalidade }\end{array}$ & $\begin{array}{c}14 \mathrm{~h} \text { às } \\
19 \mathrm{~h}\end{array}$ & Aula & $\begin{array}{l}\text { 10 Bloco: Renato Nogueira } \\
\text { (UFRRJ) } \\
\text { 2o Bloco: Katiuscia Ribeiro } \\
\text { (Quilombo Kilombá); } \\
\text { Jorge Felipe Gomes, Letícia } \\
\text { Marquez e Sarah da Silva } \\
\text { (Coletivo Negras e Negros da } \\
\text { Biologia UFRJ) } \\
\text { Mediadoras: Sônia Terezinha } \\
\text { e Alessandra Nzinga }\end{array}$ & 104 \\
\hline
\end{tabular}




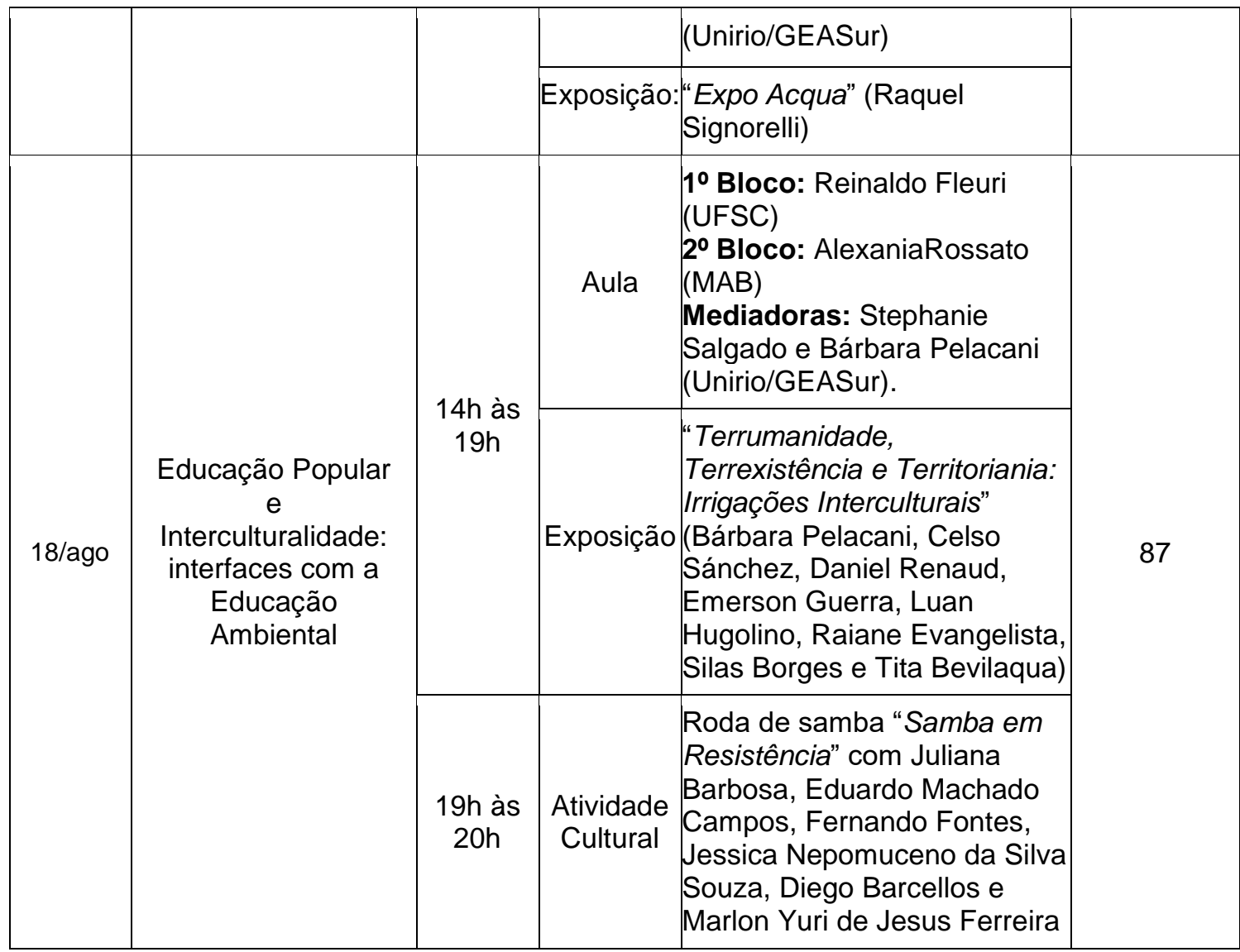

Para esta $2^{\underline{a}}$ edição do curso, mantivemos um alto índice de participação dos cursistas, com uma média de 120 participantes por aula. Desta vez, coletamos os dados das inscrições a partir do preenchimento do formulário da ferramenta Google Formulários, e foi feito um painel geral do perfil dos nossos alunos inscritos. Quanto à formação dos discentes, aproximadamente $69 \%$ dos inscritos estavam cursando a graduação ou licenciatura ou já eram graduados ou licenciados; $19 \%$ dos inscritos eram mestres ou estavam cursando o mestrado; $9 \%$ dos inscritos eram doutores ou doutorandos; $3 \%$ dos inscritos possuíam o Ensino Médio.

Mesmo havendo um recorte majoritário de universitários no perfil dos cursistas, esses dados convergem com a proposta metodológica do curso, tendo em vista os diferentes graus de formação destes e suas diferentes instituições de ensino - recebemos alunos de 17 universidades do Estado, dentre elas públicas e privadas. Se analisarmos os convidados presentes em cada dia de curso, perceberemos que esta mesma linha teórico-metodológica 
foi seguida, uma vez que havia um acadêmico e um representante de movimento social (e/ou população tradicional) em cada aula.

Importante ressaltar que em todas as edições do curso preconizamos por organizar, junto com os cursistas, um lanche coletivo. Uma mesa era disposta na entrada do auditório e a cada encontro os cursistas alocavam suas contribuições de comidas e bebidas. Esse momento se mostrou de extrema importância para as trocas e diálogos, e gradativamente fomos diminuindo o tempo das mesas e aumentando o tempo do intervalo de 15 minutos (2017) para 30 minutos (2018), chegando em 1 hora (2019). Além disso, nesta $2^{a}$ edição incorporamos mais atividades como:

1) Aula de campo na Aldeia Maracanã, a pedidos de Mônica Lima, liderança indígena local, como forma de fortalecimento da Universidade Indígena. Essa aula foi conduzida pelos indígenas, e mediada pela professora Inny Accioly.

\section{2) Oficina "O Corpo Político: dança como ação coletiva entre a América}

Latina e os Estados Unidos” buscando, através das danças latinas, debater nossa formação cultural e a relação ambiental, ministrada pela professora Camila Daniel (UFRRJ), em parceria com estudantes e imigrantes latinos. Essa foi uma atividade opcional, num sábado pela manhã antes do curso de extensão, o que pode ter ocasionado uma baixa adesão por parte dos participantes. Ainda assim, aos que estiveram presentes (15 pessoas), 0 momento foi leve e de intenso aprendizado. Aprendemos com elas que as lutas na Latino-América se fazem também com alegria, e que a própria alegria é uma luta. Usando o do ritmo do Tondero para ilustrar essa discussão, Camila Daniel nos contou que por trás do ritmo dançante e alegre da canção "La bamba", primeira música latina a chegar ao topo de Billboard, na verdade se está contando o histórico de colonização e de pirataria ocorrido nas rotas do Altântico. Aprendemos que a dança, além de nos conectar com as pessoas, em diversas culturas afro-latinas, nos conecta também com a natureza. Dançadas e sentidas com o pé no chão, tocando a terra, pisando firme, invocam à ancestralidade, como é o caso do Festejo - dança afro-peruana que mimetiza os movimentos de cortejo de aves.

3) Trabalho final opcional, com o intuito de receber as reflexões dos cursistas 
sobre alguns eixos temáticos e organizar um e-book, visando fortalecer a construção e a consolidação de uma Educação Ambiental de Base Comunitária. Estamos em fase de editoração deste material.

Cabe ressaltar que seguimos fortalecidos em nossa estratégia de oferecer a 3a edição do Curso de Extensão pelos encaminhamentos tirados na plenária final do III Congresso de Ecologia Política Latino-Americana, realizado em março de 2019 na Universidade Federal da Bahia (UFBA), onde se entendeu como prioritário ao fortalecimento do campo da Ecologia Política a oferta de cursos, disciplinas e seminários sobre a temática. Ou seja, essa é uma articulação que não fortalece apenas ao campo da $E A$, mas também da Ecologia Política.

Tendo em vista a crescente busca por formação nesta temática - que pode ser observada pelo aumento considerável de inscritos da $1^{\underline{a}}$ para a $2^{\underline{a}}$ edição do curso -, e buscando fortalecer o acesso ao máximo de pessoas, para a 3 $3^{a}$ edição do curso organizamos a transmissão online das aulas, bem como disponibilizamos em canal do YouTube (GEASur/Unirio) e do Facebook (GEASur) as palestras completas de cada aula, como forma de gerar material didático sobre os temas abordados.

Esse passo se mostrou muito acertado, tendo em vista que o interesse pela 3aㅗ edição do curso foi surpreendente: recebemos 472 inscrições, e mesmo após o encerramento do período de inscrição, diversas pessoas continuaram a entrar em contato solicitando participar do curso, gerando mais 53 inscrições, totalizando 525 inscritos. Além das exposições artísticas, nesta edição contamos com atrações culturais ao final de cada aula, potencializando a interface da Educação Ambiental com as Artes.

Tendo em vista o momento de cortes orçamentários que as Universidades públicas estão enfrentando, convidamos personalidades da academia e de movimentos sociais de fora do Estado para participarem por vídeo conferência. Contudo, para evitar qualquer falha no sistema de internet, solicitamos o envio de um vídeo, com uma fala de 10 a 15 minutos dos convidados. Essas contribuições enriqueceram enormemente o curso, além de 
contribuírem para a produção de material didático de qualidade sobre as temáticas abordadas, de fácil acesso e disseminação ${ }^{9}$.

Tabela 3- Programação do III Curso de Extensão (2019)

\begin{tabular}{|c|c|c|c|c|c|}
\hline Data & Tema do Dia & Horário & Atividade & Convidados & Participantes \\
\hline \multirow[t]{3}{*}{ 13/jul } & \multirow[t]{3}{*}{$\begin{array}{l}\text { Educação } \\
\text { Ambiental } \\
\text { desde elSur e } \\
\text { Ecologia } \\
\text { Política }\end{array}$} & $\begin{array}{l}14 \mathrm{~h} \text { às } \\
19 \mathrm{~h}\end{array}$ & Aula & $\begin{array}{l}\text { 10 Bloco: Celso Sánchez } \\
\text { (Unirio) e Inny Accioly (UFF- } \\
\text { AR) } \\
\text { 2o Bloco: Claudia Miranda } \\
\text { (Unirio) e Seimour Souza } \\
\text { (Unirio/Coletivo Luiza Mahin) } \\
\text { Vídeo: Felipe Milanez (UFBA) } \\
\text { Mediação: Stephanie Salgado }\end{array}$ & \begin{tabular}{|l|} 
Presencial: 210 \\
Online: 31 \\
Total: $\mathbf{2 4 1}$
\end{tabular} \\
\hline & & $\begin{array}{c}14 \mathrm{~h} \text { às } \\
19 \mathrm{~h}\end{array}$ & Exposição & Lorena (De Aterrar) & \\
\hline & & $\begin{array}{l}19 \mathrm{~h} \text { às } \\
20 \mathrm{~h}\end{array}$ & $\begin{array}{l}\text { Atração } \\
\text { Cultural }\end{array}$ & $\begin{array}{l}\text { Jongo Guapimirim Afrolaje e } \\
\text { Cia Mariocas }\end{array}$ & \\
\hline \multirow[t]{3}{*}{ 20/jul } & \multirow{3}{*}{$\begin{array}{l}\text { Educação } \\
\text { Ambiental, } \\
\text { Justiça } \\
\text { Ambiental e } \\
\text { Ecologia } \\
\text { Política }\end{array}$} & $\begin{array}{l}14 \mathrm{~h} \text { às } \\
19 \mathrm{~h}\end{array}$ & Aula & $\begin{array}{l}\text { 10 Bloco: Cleonice Puggian } \\
\text { (UERJ-FFP) } \\
\text { 2o Bloco: Alessandra Nzinga } \\
\text { (UMNP) } \\
\text { Vídeo: Frederico Loureiro } \\
\text { (UFRJ) e Philippe Layrargues } \\
\text { (UnB) } \\
\text { Mediação: Marcelo Aranda e } \\
\text { Bárbara Fortes } \\
\end{array}$ & $\begin{array}{l}\text { Presencial: } 161 \\
\text { Online: } 60 \\
\text { Total: } \mathbf{2 2 1}\end{array}$ \\
\hline & & $\begin{array}{c}14 \mathrm{~h} \text { às } \\
19 \mathrm{~h}\end{array}$ & Exposição & $\begin{array}{l}\text { Vídeos Terreiros/Projeção } \\
\text { (Chico Serragrande) } \\
\end{array}$ & \\
\hline & & $\begin{array}{l}19 \mathrm{~h} \text { às } \\
20 \mathrm{~h}\end{array}$ & $\begin{array}{l}\text { Atração } \\
\text { Cultural }\end{array}$ & $\begin{array}{l}\text { A AR CIA - A Arte Resiste } \\
\text { Companhia de Intervenções } \\
\text { Artísticas }\end{array}$ & \\
\hline \multirow{3}{*}{ 27/jul } & \multirow{3}{*}{$\begin{array}{l}\text { Metodologias } \\
\text { de Base } \\
\text { Popular: } \\
\text { Militância } \\
\text { Investigativa }\end{array}$} & $\begin{array}{c}9 \mathrm{~h} \text { às } \\
12 \mathrm{~h}\end{array}$ & Oficina & $\begin{array}{l}\text { "Pacha, defendendo a terra. } \\
\text { Extrativismo, conflitos e } \\
\text { alternativas na América Latina } \\
\text { e Caribe” } \\
\text { Ministrantes:María Villarreal, } \\
\text { Leilane Santos e Seimour } \\
\text { Souza (GRISul/Unirio) } \\
\end{array}$ & \\
\hline & & $\begin{array}{l}14 \mathrm{~h} \text { às } \\
19 \mathrm{~h}\end{array}$ & Aula & $\begin{array}{l}\text { 10 Bloco: Marina Praça (PACs) } \\
\text { 2o Bloco: Coletiva Popular de } \\
\text { Mulheres da Zona Oeste } \\
\text { (Projeto Militiva) } \\
\text { Vídeo: Thiago Ávila (Coletivo } \\
\text { Subverta) } \\
\text { Mediação: Daniel Renaud } \\
\text { Camargo } \\
\end{array}$ & $\begin{array}{l}\text { Presencial: } 142 \\
\text { Online: } 36 \\
\text { Total: } 178\end{array}$ \\
\hline & & $\begin{array}{c}14 \mathrm{~h} \text { às } \\
19 \mathrm{~h}\end{array}$ & Exposição & $\begin{array}{l}\text { "Banheiro" (M. Luiza Sucekind) } \\
\text { e "A COR DAR" } \\
\text { (RaíssaThebergue) }\end{array}$ & \\
\hline
\end{tabular}

\footnotetext{
${ }^{9}$ Todos os vídeos o III Curso de Extensão em Educação Ambiental e Ecologia Política na América Latina podem ser encontrados no canal do YouTube do GEASur/Unirio: https://www.youtube.com/channel/UCLu5JM46V79 qSapQ7Hsu1A
} 


\begin{tabular}{|c|c|c|c|c|c|}
\hline & & $\begin{array}{c}19 \mathrm{~h} \text { às } \\
20 \mathrm{~h}\end{array}$ & $\begin{array}{l}\text { Atração } \\
\text { Cultural }\end{array}$ & $\begin{array}{l}\text { CAN - Cineclube Atlântico } \\
\text { Negro: Documentário } \\
\text { Anamnese, } 2016 \text { (Clementino } \\
\text { Jr.) } \\
\end{array}$ & \\
\hline \multirow[t]{3}{*}{ 10/ago } & \multirow[t]{3}{*}{$\begin{array}{l}\text { Soberania } \\
\text { Alimentar e } \\
\text { Ecofeminismos }\end{array}$} & $\begin{array}{c}14 \mathrm{~h} \text { às } \\
19 \mathrm{~h}\end{array}$ & Aula & $\begin{array}{l}\text { 19 Bloco: Catalina Pardo } \\
\text { (EICOS/UFRJ) } \\
\text { 2o Bloco: Luana Carvalho } \\
\text { (MST) e Vanessa Schottz } \\
\text { (UFRJ-Macaé) } \\
\text { Vídeo: Camila Mantovanni } \\
\text { (Igreja Batista do Caminho) e } \\
\text { Suzani Cassiani (UFSC) } \\
\text { Mediação: Carolina Alves }\end{array}$ & $\begin{array}{l}\text { Presencial: } 135 \\
\text { Online: } 34 \\
\text { Total: } 169\end{array}$ \\
\hline & & $\begin{array}{c}14 \mathrm{~h} \text { às } \\
19 \mathrm{~h}\end{array}$ & Exposição & H2Orizontes & \\
\hline & & $\begin{array}{c}19 \mathrm{~h} \text { às } \\
20 \mathrm{~h}\end{array}$ & $\begin{array}{l}\text { Atração } \\
\text { Cultural }\end{array}$ & Amora Pêra & \\
\hline \multirow[t]{3}{*}{ 24/ago } & \multirow{3}{*}{$\begin{array}{l}\text { Neoextrativismo } \\
\text { e pedagogias } \\
\text { das lutas } \\
\text { sociais }\end{array}$} & $\begin{array}{c}14 \mathrm{~h} \text { às } \\
19 \mathrm{~h}\end{array}$ & Aula & $\begin{array}{l}\text { 10 Bloco: Raquel Giffoni Pinto } \\
\text { (IFRJ/Poemas) } \\
\text { 2o Bloco: Alexandre Anderson } \\
\text { (AHOMAR) } \\
\text { Vídeo: Dulce Pereira (UFOP) } \\
\text { Mediação: Clementino Jr. e } \\
\text { Marcelo Aranda. } \\
\end{array}$ & $\begin{array}{l}\text { Presencial: } 140 \\
\text { Online: } 41 \\
\text { Total: } \mathbf{1 8 1}\end{array}$ \\
\hline & & $\begin{array}{c}14 \mathrm{~h} \text { às } \\
19 \mathrm{~h}\end{array}$ & Exposição & $\begin{array}{l}\text { Museu das Remoções (Vila } \\
\text { Autódromo) e Marcha das } \\
\text { Margaridas em fotografia } \\
\text { (projeção) }\end{array}$ & \\
\hline & & $\begin{array}{c}19 \mathrm{~h} \text { às } \\
20 \mathrm{~h}\end{array}$ & $\begin{array}{l}\text { Atração } \\
\text { Cultural }\end{array}$ & $\begin{array}{l}\text { Indiana Nomma - tributo à } \\
\text { Mercedes Sosa }\end{array}$ & \\
\hline
\end{tabular}

Buscando computar em números o crescimento da procura pelo curso, temos os seguintes dados:

Tabela 4- Dados sobre procura e participação dos cursistas nas três edições do curso de extensão em Educação Ambiental de Base Comunitária e Ecologia Política na América Latina

\begin{tabular}{|c|c|c|c|c|}
\cline { 2 - 5 } \multicolumn{1}{c|}{} & \multicolumn{2}{c|}{ Inscrições } & Formados & Evasão \\
\cline { 2 - 5 } \multicolumn{1}{c|}{} & Total & Efetivadas & & \\
\hline $\mathbf{2 0 1 7}$ & 204 & 122 & 100 & $18 \%$ \\
\hline $\mathbf{2 0 1 8}$ & 320 & 176 & 115 & $35 \%$ \\
\hline $\mathbf{2 0 1 9}$ & 525 & 241 & 206 & $14 \%$ \\
\hline
\end{tabular}

Por inscrições efetivadas estamos computando o número máximo de pessoas que compareceram presencialmente. Todos aqueles que compareceram a pelo menos 3 aulas, obtendo $60 \%$ de frequência, receberam um certificado de participação e conclusão do Curso de Extensão. Sendo 
assim, a taxa de evasão foi calculada com base na diferença entre as inscrições efetivadas e o número de participantes formados no curso. Outro dado relevante é que em dois anos o número de cursistas dobrou.

Como se pode observar houve uma variação de 50-40\% de efetivação das inscrições dos cursistas, mas ano após ano o interesse pela temática vem aumentando. E mesmo com uma maior taxa de evasão, quantitativamente se está formando mais educadores ambientais através do curso de extensão. Ao longo de três anos, formamos 421 pessoas.

Nesta $3^{a}$ edição do curso, não conseguimos viabilizar uma aula de campo, mas mantivemos uma oficina temática num sábado pela manhã, oferecida pelo Grupo de Relações Internacionais do Sul Global (GRISul/Unirio), que contou com a participação de 24 pessoas. E expandimos as atividades culturais como encerramento de todas as aulas.

Como novidade, para além da transmissão online e dos convidados por vídeo, se organizou o I Fórum de Educação Ambiental de Base Comunitária e Ecologia Política na América Latina, no dia 17 de agosto de 2019, buscando dar vazão a demanda dos cursistas por mais momentos de troca entre eles e de compartilhamento de experiências. A ideia surgiu durante a segunda aula do curso. Na terceira aula foi apresentada a proposta e disponibilizada ficha de inscrição para os interessados. Também foi enviado e-mail explicativo e foram aceitas inscrições via formulário eletrônico.

Obtivemos 43 inscritos para o Fórum, que foram organizados em grupos temáticos de debate, com a intenção de que fossem compartilhadas suas experiências em 10 minutos, além de haver sido reservado um momento para a plenária final, com todos os grupos juntos. Contudo, no dia 17 de agosto, apenas 20 pessoas compareceram ao Fórum, e dessa forma optamos por não fazer a subdivisão dos grupos temáticos, e os cursistas aceitaram reduzir seu tempo de apresentação para 5 minutos. Iniciamos com uma rodada de apresentações gerais, seguida pela apresentação dos trabalhos e discussões.

Foi interessante observar que, no próprio curso, iniciativas surgiram e estão se concretizando, como por exemplo, um espaço de horta urbana na Barra da Tijuca e outro em Caxias. Também recebemos relatos de coletivos 
que se auto-organizaram para estudar sobre PANCs (plantas alimentícias nãoconvencionais) e já plantaram algumas espécies em seus quintais e na universidade. Ou seja, o curso, para além de um espaço de formação de educadores e/ou ativistas socioambientais, é também um local de tessituras de redes e encontros, de práxis - reflexão e ação, ação refletida, para além do GEASur.

\section{CONSIDERAÇÕES FINAIS}

O curso de extensão trouxe para a prática as reflexões da Educação Ambiental de Base Comunitária, em diálogo com a Ecologia Política, procurando as interfaces com a realidade Latino-Americana. Tais reflexões vêm sendo desenvolvidas na academia em diálogo com a educação popular, ao criar um ambiente para pensar e atuar junto aos movimentos sociais, numa reflexão sobre o papel da universidade pública na sociedade.

O diálogo de saberes entre os professores universitários e as lideranças de movimentos sociais foi uma das expressões da potência do curso, assim como a sua articulação com as artes. A transmissão online se demonstrou muito interessante para garantir o acesso de outros públicos, em outros estados e países, sem gerar custos adicionais aos envolvidos.

Ecologia Política e Educação Ambiental de Base Comunitária foram implementadas como processos para se pensar a educação a partir de debates sobre os conhecimentos socioambientais presentes na crítica aos projetos de desenvolvimento; análises de conjuntura problematizaram o momento políticoeconômico e suas interferências na universidade pública e na atuação dos sujeitos nos territórios; debates com e sobre políticas públicas de educação e ambiente, se estabeleceram, mantendo o caráter de olhar desde os oprimidos. Como ponto mais forte do curso destaca-se a presença de representantes de grupos étnicos e raciais, mulheres que são referência nas suas áreas e lideranças dos movimentos sociais, tanto apresentando as aulas quanto participando dos diálogos como cursistas. 
Como podemos observar com a análise do curso acima descrito, ele proporcionou a ampliação do diálogo entre os saberes, bem como, do papel social da universidade, muitas vezes vista como instituição detentora do saber "verdadeiro", único, permitindo que professores e alunos veja os sujeitos sociais como produtores de saberes. Também promoveu um re-existir da práxis emancipadora e decolonial, proposta por Paulo Freire, Catherine Walsh, Santiago Arboleda Quiñonez entre outros. Também pudemos discutir que essa luta e disputa não é só uma questão brasileira. Na América Latina, o ecoetnogenocídio (Quiñonez, 2018) tem aumentado muito nos últimos anos, inclusive com a morte das lideranças socioambientalistas, principalmente de mulheres.

Por esse motivo e para ampliar o diálogo e o processo de integração latino-americana, seria interessante a implementação de cursos como esse, incluindo a modalidade à distância, que possam integrar essas lutas e esses povos, ampliando as instituições de ensino superior desses países e os movimentos sociais dos mesmos. Em nossa 3a edição caminhamos no sentido de tal ampliação, através da transmissão online em mídias sociais abertas. Seguiremos neste caminho e em vias de ampliação para a próxima edição. Percebemos também com esse trabalho a urgência de fazermos chegar tais debates aos professores de educação básica, das escolas públicas de periferia, pois temos identificado uma imensa demanda oriunda desse segmento durante os cursos de extensão. Sendo assim, pretendemos construir a 4⿳a edição já apontando para essa segmentação e buscando a internacionalização da proposta.

Outro ponto potente e também basilar para o sucesso do curso foi à incorporação de demandas trazidas tanto pelo campo da Ecologia Política quanto pelos participantes do curso, como as discussões sobre neoextrativismos e ecofeminismos, além da constante abertura de espaços para trocas entre cursistas e convidados.

Trazer os aportes do giro decolonial para as discussões no campo da EA de Base Comunitária permite a transversalidade de temas com abordagem potente para a EA, como o racismo ambiental e os ecofeminismos, já que com 
o descobrimento das Américas houve tanto a racialização da população mundial com a criação das identidades subalternas de negros e índios, e a instauração de um conflito ambiental como mito fundacional da América Latina. Não há Educação Ambiental Crítica possível fora dessa contextualização. 


\section{REFERÊNCIAS}

ACSELRAD, Henri. Justiça ambiental: ação coletiva e estratégias argumentativas. In: ACSELRAD, Henri, et al (Ed.). Justiça ambiental e cidadania. 2.ed. Rio de Janeiro: Relume Dumará: Fundação Ford, 2004. p.2337. ISBN 8573163534.

ALIMONDA, Hector. La colonialidad de la naturaliza: una aproximación a la ecología política latinoamericana in ALIMONDA, Hector (coord.). La naturaleza colonizada: ecología política y minería en América Latina. Buenos Aires: CLACSO, 2011.

ALIMONDA, Héctor; TORO, CatalinaPérez; MARTíN, Facundo (coord.). Ecología política latinoamericana: pensamiento crítico, diferencia latinoamericana y rearticulación epistémica. $1^{\underline{a}}$ ed. Ciudad Autónoma de Buenos Aires: CLACSO; México: Universidad Autónoma Metropolitana; Ciudad Autónoma de Buenos Aires: Ciccus, 2017.

AQUINO, Mahalia Gomes de Carvalho. Aprender a ser atingido: Educação e lutas socioambientais diante da tragédia do rompimento da Barragem de Fundão (Mariana - MG) no Rio Doce e afluentes. Dissertação (Mestrado em Educação) - Universidade Federal do Estado do Rio de Janeiro. 2018.

BULLARD, Robert. "Ética e racismo ambiental". Revista Eco 21, ano XV, № 98, janeiro/2005.

CAMARGO, Daniel Renaud. Lendas, Rezas e Garrafadas: Educação ambiental de base comunitária $e$ os saberes locais no vale do Jequitinhonha. Dissertação (Mestrado em Educação) - Programa de PósGraduação em Educação, Universidade Federal do Estado do Rio de Janeiro, Rio de Janeiro, 2017.

DUSSEL, Enrique. 1492 o encobrimento do outro: a origem do mito da modernidade. Tradução Jaime A. Clasen. Petrópolis: Vozes, 1993.

FREIRE, Paulo. Pedagogia da Autonomia. Editora: Paz e Terra, 2007.

GONÇALVES, Nadia Gaioffato. "Indissociabilidade entre Ensino, Pesquisa e Extensão: um princípio necessário". PERSPECTIVA, Florianópolis, v. 33, n. 3, p. 1229 - 1256, set./dez. 2015.

LAYRARGUES, Philippe Pomier; LIMA, Gustavo Ferreira da Costa. "As macrotendências político-pedagógicas da educação ambiental brasileira". Ambiente \& Sociedade. São Paulo, v. XVII, n. 1, p. 23-40, jan.-mar, 2014.

"Mapeando as macro-tendências político-pedagógicas da Educação Ambiental contemporânea no Brasil". In: VI Encontro Pesquisa e Educação Ambiental - EPEA. Ribeirão Preto: EPEA, set. 2011. 
LAYRARGUES, Philippe Pompier (coord).Identidades da Educação Ambiental Brasileira. Ministério do Meio Ambiente. Diretoria de Educação Ambiental - Brasília, 2004.

A crise ambiental e suas implicações na educação. In: José da Silva Quintas. (Org.). Pensando e praticando a educação ambiental na gestão do meio ambiente. 2ed.Brasília: IBAMA, 2002, p. 159-196.

LEFF, Enrique. Racionalidade Ambiental: a reapropriação social da natureza. Rio de Janeiro: Civilização Brasileira, 2006.

LOUREIRO, Carlos Frederico Bernardo (Org.). Educação ambiental, gestão pública, movimentos sociais e formação humana: uma abordagem emancipatória. 1ed. São Carlos: RIMA, 2009, p. 1-14.

LOUREIRO, Carlos Frederico Bernardo; LAYRARGUES, Phillippe Pompier. "Ecologia política, justiça e educação ambiental crítica: perspectivas de aliança contra-hegemônica". Revista Trab. educ. saúde. vol.11 n.1 Rio de Janeiro Jan./Abr. 2013.

MENEZES, Anne Kassiadou [et al] (org.). Educação Ambiental desde El Sur. Macaé: Editora NUPEM, 214 p.,2018.

MENEZES, Anne Kassiadou. Escolas Sustentáveis e Conflitos Socioambientais: Reflexões sobre o programa governamental das Escolas Sustentáveis sob a ótica da Justiça Ambiental. Dissertação (Mestrado em Educação) - Universidade Federal do Estado do Rio de Janeiro. 2018.

MIGNOLO, Walter. D. El Pensamiento Decolonial: Desprendimiento y Apertura. Un manifesto. In: CASTRO-GÓMEZ, Santiago; GROSFOGUEL, Ramón (orgs). El Giro Decolonial: Reflexiones para una diversidad epistemica más alládel capitalismo global. Bogotá: Siglo del hombre Editores, 2007.

MOTA NETO, João Colares da. Por uma pedagogia decolonial na América Latina: reflexões em torno do pensamento de Paulo Freire e Orlando Fals Borda. Curitiba: CRV, 2016.

OLIVEIRA, Carolina Alves Gomes de; SÁNCHEZ, Celso Pereira. “Educação ambiental, justiça ambiental e questões de gênero: a perspectiva de um grupo de educadoras ambientais comunitárias de Magé, RJ". Rev. Eletrônica Mestr. Educ. Ambient. Rio Grande, v. 35, n. 1, p. 151-170, jan./abr. 2018. E-ISSN 1517-1256

PELACANI, Bárbara. As lutas que educam na América Latina: A Educação Ambiental que emerge do conflito pela água em Cachoeiras de Macacu com um olhar desde a Colômbia. Dissertação (Mestrado em Educação) Programa de Pós-Graduação em Educação, Universidade Federal do Estado 
do Rio de Janeiro, Rio de Janeiro, 2018.

PORTO-GONÇALVES, Carlos Walter. "Da geografia às geo-grafias: um mundo em busca de novas territorialidades". In: La guerra infinita. Hegemonía y terror mundial. CECEÑA, Ana Esther; SADER, Emir. [Orgs].Rio de Janeiro, CLACSO. Vozes. LPP, 2002

QUIJANO, Aníbal. Colonialidad del poder y clasificación social. In CastroGómez, Santiago y Grosfoguel, Ramón (comps.). El giro decolonial: reflexiones para una diversidad epistémica más alládel capitalismo global. Bogotá: Siglo del Hombre/Universidad Central/Instituto de Estudios Sociales Contemporáneos y Pontificia Universidad Javeriana / Instituto Pensar, 2007.

QUIÑONEZ, Santiago Arboleda. "Defensa Ambiental, Derechos Humanos y ecogenoetnocidio afrocolombiano". Pesquisa em Educação Ambiental, vol.13, n.1-p.10-27, 2018. DOI: http://dx.doi.org/10.18675/2177-580X.vol13.n1.p10-27

RIOS, Natália Tavares. Educação Ambiental e Direitos Humanos na formação inicial de professores de Ciências Biológicas. Tese (Doutorado em Educação), Programa de Pós-Graduação em Educação. Pontifícia Universidade Católica do Rio de Janeiro - PUC. 2016.

SANTOS, Boaventura de Sousa. Para além do Pensamento abissal: das linhas globais a uma ecologia de saberes. In: SANTOS, Boaventura; MENESES, Maria Paula. Epistemologias do Sul. Editora Cortez, 1aㅡ Ed, 2010.

SILVA, Júlio Vitor Costa da. Sociedades de água do Morro da Formiga: subsídios para educação ambiental de base comunitária e ecologia de saberes em uma favela carioca. Dissertação (Mestrado em Educação) - Universidade Federal do Estado do Rio de Janeiro, Rio de Janeiro, 2016.

STORTTI, Marcelo Aranda. Aprender a resistir e resistir para aprender: um estudo sobre a educação ambiental que emerge das lutas de atingidos pela indústria do petróleo no Rio de Janeiro. Tese (Doutorado em Educação) - Centro de Ciências Humanas e Sociais, Universidade Federal do Estado do Rio de Janeiro. Rio de Janeiro, p. 179, 2019.

TAVARES, Paula. Ritos de passagem. Luanda: União dos Escritores Angolanos, 1985, p. 30-31.

TOZONI-REIS, Marília Freitas de Campos. Contribuições para uma pedagogia crítica na educação ambiental: reflexões teóricas. In: LOUREIRO, Carlos Frederico Bernardo (org.) [et al.]. A questão ambiental no pensamento crítico: natureza, trabalho e educação. Rio de Janeiro: Quartet, 2007.

WALSH, Catherine. ¿Interculturalidad y (de)colonialidad? Gritos, grietas y siembras desde Abya-Yala. In: DINIZ, Alai Garcia, et. al. (orgs.). Poéticas e políticas da linguagem em vias de descoloniazação. Pedro \&Joâo Editores: 
São Carlos-Brasil. 2017.

Catherine. "[Interculturalidad] Políticas y significados conflictivos". Nueva Sociedad, v.165, enero-febrero, p.121-133, 2000.

WANDERLEY, Luiz Jardim [et al]. "Desastre da Samarco/Vale/BHP no Vale do Rio Doce: aspectos econômicos, políticos e socioambientais". Ciência e Cultura, v. 68, p. 30-35, 2016. 